\title{
MODEL OF MATURITY (MOM) : LESSONS FOR NEW SHG'S
}

\author{
'Dr. K. Rajendran, MBA., Ph.D.,
}

\begin{abstract}
This article analyses the problems and constraints faced by the matured $n$ SHG members in Vellore district in Tamil Nadu. The researcher collected responses from 450 women respondents from two blocks in Vellore district in Tamil Nadu and the study concludes that rotation of leaders, lack of cooperation and family member criticism are the major problems experiences by the matured SHGs which will be a lesson to the newly formed SHGs. Discriminant analysis was used in analysing the data collected from the women respondents. The study will be helpful to the Self Help Promoting Institutions (SHPI) rural development practitioners and NGOs to ensure that these problems do not recur or and in evolving an efficient mechanism to handle the issues.
\end{abstract}

Keywords : Self Help Groups-Micro finance-income generating activities-Criticism-

Non Governmental Organisations

MODEL OF MATURITY (MOM): What the new SHGs of India should learn from matured SHGs?

\section{INTRODUCTION}

The governments - both federal and in a number of states - have been encouraged with the success of the SHG and micro-finance as a strategic asset oriented approach and extend its scope and investments. For any strategic approach to be sustainable, it is always profitable to track the deficiencies-constraints and problems faced on the way and cause corrections; they may be at policy level and during implementation. The SHG and micro-finance approach is no exception.

The researchers found quite a few issues associated with the commencement, continuation and sustainability aspects of SHG activity. When any SHG starts any income generating activity, some of the problems that surface. generally speaking, nclude, among others, timing [when to start], location [where to start the activity], source of raw materials [logistics], reaching market [how to sell the products], source of finance, and, many times, non cooperation of other non SHG neighbourhood members would come to surface. Even family members may not like women going out frequently for group activities or taking up new occupation [other than the one followed by the family men]; they may sometimes criticize and may not extend necessary support to the women. Sometimes those who are not connected to the group or family may create problems.

The mature Self Help Groups (SHGs) or the SHGs which are relatively older might have faced more problems and gained experiences from various situations. So, a study on these groups might help the recently formed groups by providing insights for problem handling, eliminating or reducing the problems in functional or non functional forms and other constraints

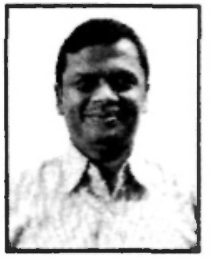

Dr. K. Rajendran, MBA., Ph.D.,

Formerly Research Scholar,

Department of Management Studies, School of Management,

Pondicherry University.

E-mail : kraj1962@ gmail.com

Mob : 09500086766 


\section{REVIEW OF LITERATURE}

Many studies indicated the problems and constraints of micro finance through SHG. The recent studies on microfinance highlights some issues like the lack of access to formal credit(Wenner and Chalmers 2001), lack of funds, delinquency in repayment and political intervention in the identification of activities (Rahman 2002), political interference in the selection of the beneficiaries, lack of timely and adequate credit and lack of women oriented schemes (Vadivoo and Sekar 2004), Lack of clear information and guidance and low support from the family (Vanitha and Krishnamurthy 2004), inadequate capital, delay in sanctioning of loan and inadequate understanding of market and market conditions ( Ramanunny 2005), lack of orientation and initiative of bank staff to the concept and the needs of Self Help Groups(Rao 2005), loans to members not based on purpose of loans, irregular group meetings, lack of proper maintenance of book keeping(Chaim 2006), restrictive government procedure (Bhuvaneswaran 2006), lack of training (Lalitha 2007; Swain 2009), low returns and overemphasis on repayment (Ahmad 2006), inadequate loans and long waiting period to get loans (Ghate2007), lack of cooperation and understanding among members, conflict between leaders and members based on caste and locality (Kumari and Malathi 2009), lack of capital and labour (Kallur 2009).

\section{STATEMENT OF THE PROBLEM}

The above brief review of literature has shown some of the problems and constraints in microfinance. There was no study was conducted in Vellore district about the problems relating to micro finance among rural women. Though many studies were conducted in various districts of Tamil Nadu, no study was conducted in Vellore district to explore the problems and constraints of SHG micro-finance. Moreover, Vellore district in Tamil Nadu is one of the important districts, the researcher has chosen Vellore district for the current study. With these issues, the main focus of this study is to the problems in micro finance in Vellore district. With this background a study was conducted in Vellore district of Tamil Nadu(India) focussing on SHGs formed in the last ten years. with 450 women members of SHGs in two blocks. SHGs formed in and before 2005 and before were grouped in group I $(N=178)$ and the groups which formed after 2005, i.e. during 2006 and 2007 were classified in group $\|(\mathrm{N}=272)$.

\section{OBJECTIVES OF THE STUDY}

The present study is undertaken with the following specific objective:

To identify the problems in micro finance through SHGs in Vellore district.

\section{METHODOLOGY}

The present study is a descriptive one and the required primary data were collected by using a structured questionnaire designed exclusively for this study. The data were collected from primary sources through direct contact with the women SHG groups during the period 2008-09. Two blocks in Vellore district such as Natrampalli and Nemili were selected for the study. as the two blocks have similarities in number of SHGs and population below poverty line. The researcher has selected 225 respondents using random sampling from each block representing 90 SHGs formed in the last ten years and 5 respondents were selected from each SHG. Therefore total sample of 450 respondents was collected and analysed.

\subsection{DISCRIMINANT ANALYSIS}

Discriminant analysis is a statistical technique which allows the researcher to study the difference between two or more groups of objects with respect to several variables simultaneously. A discriminant model with family member criticism, non-member criticism, criticism by banks, lack of training, lack of time, lack of support in family and inadequate loan amount as independent variables and groups' formation as dependent measure has been developed to identify whether the recently formed groups or older groups are discriminated by the set of problems faced.

\section{AN INTRODUCTION TO THE VARIABLES}

\subsection{Family members' criticism/ problems}

Problems in the family are an important issue for women. When they enjoy cooperation from family 
members, especially from elders in rural areas, women can become successful micro-entrepreneurs. Vanitha and Krishnamurthy (2004) identified family restrictions as a major constraint in India. In Tanzania, Makumbe et al (2005) found that cooperation from the husbands of women contributed to the success of microfinance. Thus, to bring out the significance of family members criticism, this variable is included in the model.

\subsection{NON SELF HELP GROUP MEMBER CRITICISM.}

There are non-members of Self Help Groups who may criticize the members of Self Help Group and micro finance. To understand the significance of the criticism by non members influence on the groups, the variable is included in the model.

\subsection{Criticism by banks}

Sometimes bank officials may criticize the Self Help Group members and they may think lending to small borrowers is a burden/overwork to them and it is widely believed that rural borrowers may not repay in time. Lack of initiative by the bank staff, bank's insistence on collateral and discouragement by the banks as it is more work for them(Rao 2005), lack of confidence among banks to finance SHGs and treatment of entire savings as collateral Chaim (2006) and over emphasis on repayment Ahmad (2006) were some of the constraints identified by the earlier researchers. In Andhra Pradesh, a study was conducted by APMAS during 2005 which reported that staff in some of the branches behaved indecently/ or talked arrogantly with the leaders and owing to this reason some of the good SHGs did not seek repeat loans. To bring out the importance of criticism of the employees of the banks and its ability to discriminate the newer and older group, the variable is considered in the model.

\subsection{Lack of training}

Rural women, especially the first generation micro-entrepreneurs, need training to undertake income generating projects/activities. Training enables women to undertake new activities with self confidence and courage. Lack of training (Lalitha 2007, Swain 2009), lack of technical know how
(Ramanunny 2005) and lack of clear information and guidance (Vanitha and Krishnamurthy 2004) were identified as constraints by prior studies. Thus, to bring out the training component's influence in the study context, the variable is included the model.

\subsection{LACK OF TIME}

Women have to attend household work, they have to take care of the children and elders and the balance time only may be dedicated for group related activities and income generating activities. Mishra (2010) identified that time is a constraint for many of the rural women, particularly in the Indian context. Also, it is a fact that for many decades, women have been assuming the role of homemakers in the Indian subcontinent. Thus, to bring out the significance of time factor, it is considered in the model.

\subsection{LACK OF SUPPORT IN THE FAMILY}

Family support is an essential pre-requisite for the success of any activity undertaken by the individual and without -the support of the family nobody can achieve anything. Low support from the family (Vanitha and Krishnamurthy 2004) has been found as factor affecting the self help group's performance. To bring out the significance of the support of family members, on the two groups, the variable is included in the model.

\subsection{Inadequate loan amount}

To carry out any enterprising activity, finance is required in right quantity at right time and microfinance is one of the important inputs for micro enterprises. Lack of funds (Rahman 2002), lack of adequate credit (Vadivoo and Sekar 2004), inadequate capital (Ramanunny 2005,) small size of loans (APMAS 2005) inadequate loan (Ghate 2007) and lack of capital (Kallur 2009) are some of the factors identified by the earlier studies as the ones that affect self help groups. However, in the recent times, the central and state governments have made significant policy changes to improve the performance of SHGs through liberal extension of bank loans. To understand the impact of the policy changes, credit extension by banks is included the model. 


\subsection{DELAY IN GETTING LOAN}

Loan should be received in time and delayed sanction of loan may demotivate the entrepreneurs. Delayed financial assistance will demotivate the borrower and it may end up in misutilisation of the funds. Delay in sanction of loans (Ramanunny 2005) and long waiting period to get loans (Ghate 2007) and complex loan drawing procedure (APMAS 2005) have been brought out as major problems by earlier studies. The present model attempts to find out whether two groups differ in terms of getting loans in time.

\subsection{NON-AVAILABILITY OF RAW MATERIAL}

Raw material is the most important input for any enterprises whether it is a micro or small or major industry. To bring out the significance of the non availability of raw materials on the two groups, the variable is included in the model.

\subsection{PROBLEMS IN MARKETING}

Whatever produced should be marketed; then only there will be cash flow to the entrepreneur and there will be sustainability. Inadequate understanding of market, lack of customer awareness and poor business plan (Ramanunny 2005) and lack of understanding of goals (Bhuvaneswaran (2006) are some of the problems identified in India. Makumbe et al. (2005) found that the success of microfinance in Tanzania was due to marketing of the products. Hence this variable was included in this model to differentiate the significance between the new and older groups and it will help the rural development practitioners and decision makers.

\subsection{LACK OF COOPERATION}

Sometimes there may be lack of cooperation between members in the group and this may create a problem. Kumari and Malathi (2009) identified lack of cooperation and understanding among members and conflict between leaders and members based on caste and locality, as the main problems in India. 28 to 40 per cent drop out due to group problems in Andhra Pradesh (APMAS 2005) and astudy conducted by APMAS and EDA rural system (2006)also concluded that group conflict as reason for drop out in India. In Tanzania lack of trust among members was identified by Ssendi and Anderson (2009). Hence to study the significance of lack of cooperation among the members of the group this variable is included in the model.

\subsection{ROTATION OF LEADERSHIP IN THE GROUP}

The SHG is a voluntary association expected to function on democratic basis and there shall be rotation of leadership among members. In Andhra Pradesh, a study was conducted by APMAS during 2005 which reported that only seventeen per cent of the groups changed their leaders since the formation of the groups and most of the leaders were unwilling to give way to new leaders. In Rajasthan, a study conducted by CMF and APMAS during 2006 reported that there is hardly any rotation in the leadership even in well functioning groups and there was change in leadership only in 6 per cent of groups and the leaders are by and large given free hand in running the SHG. In order to find out the significance of rotation of leadership among the group members, this variable is included.

\subsection{OUTSIDERS PROBLEMS}

Sometimes, outsiders such as politicians or some other social groups may interfere in the affairs of microfinance and it may be a problem or a constraint for the function of group activities. Political interference in the selection of the beneficiaries relating to microfinance schemes were reported by Vadivoo and Sekar (2004) and Rahman (2002). Thus to bring out the significance of the interference of outsiders interference, the variable is included in the model.

\section{RESULTS AND DISCUSSIONS}

A stepwise discriminant analysis procedure was chosen to control the effects of multicollinearity if any. The analysis was further attempted at each of the problems to understand whether any significant differences are evident across the groups in discriminating.

$$
\begin{aligned}
Z_{1 k}= & a+W_{1} X_{1 k}+W_{2} X_{2 k}+W_{3} X_{3 k}+W_{4} X_{4 k}+ \\
& W_{5} X_{5 k}+W_{6} X_{6 k}+W_{7} X_{7 k}+W_{8} X_{8 k}+W_{9} X_{9 k} \\
& +W_{10} X_{10 k}+W_{11} X_{11 k}+W_{12} X_{12 k}+W_{13} X_{13 k}
\end{aligned}
$$


where,

$$
\begin{aligned}
& Z_{j k}=\text { discriminant } Z \text { score of discriminant function }-1 \text { for object } k \\
& a=\text { intercept } \\
& W_{i}=\text { discriminant weight for independent variable ' } i \text { '. } \\
& X_{i k}=\text { independent variable ' } i \text { ' for object ' } k \text { '. } \\
& X_{1}=\text { Family members' problems } \\
& X_{2}=\text { Non Self Help Group member criticism } \\
& X_{3}=\text { Criticism by banks related activities } \\
& X_{d}=\text { Lack of training } \\
& X_{5}=\text { Lack of time } \\
& X_{B}=\text { Lack of support in the family } \\
& X_{1}=\text { Inadequate loan amount } \\
& X_{8}=\text { Delay in getting loan } \\
& X_{9}=\text { Non-availability of raw material } \\
& X_{10}=\text { Problems in marketing } \\
& X_{11}=\text { Lack of cooperation } \\
& X_{12}=\text { Rotation of leadership in the group } \\
& X_{i s}=\text { Outsiders problems }
\end{aligned}
$$

Classification summary table provides the strength of the classification ability of the discriminant function. Overall, nearly 60.7 per cent of the cases were correctly classified by the discriminant function. Thus, it indicates that the variables in the model are highly useful for reasoning out or predicting more favourable attributes evaluations (Table 1) between the two groups

Table 1 Classification results

\begin{tabular}{|l|l|l|l|}
\hline \multirow{2}{*}{ Groups } & \multicolumn{2}{c|}{ Predicted Group Membership } & \multirow{2}{*}{ Total } \\
\cline { 2 - 3 } Group I(Groups formed in 2005 and before) & Group I & Group II & 178 \\
\hline Group II(Groups formed after 2005) & 108 & 70 & 272 \\
\hline Group I(Groups formed in 2005 and before) percent & 60.6741 & 165 & 100.0 \\
\hline Group II(Groups formed after 2005) percent & 39.3382 & 39.3259 & 100.0 \\
\hline
\end{tabular}

Source: Output of SPSS

The test of functions column (Table 2) tests the hypothesis that the means of the function(s) listed are equal across groups. Wilks' lambda is the proportion of the total variance in the discriminant scores not explained by differences among the groups. A chi-square transformation of Wilks' lambda is used along with the degrees of freedom to determine significance. Since the significance value is less than 0.05, it indicates that group means differ from each other. 
Table 2 Wilks' Lambda

\begin{tabular}{|l|c|c|c|c|}
\hline $\begin{array}{l}\text { Test of } \\
\text { Function(s) }\end{array}$ & Wilks' Lambda & Chi-square & df. & Sig. \\
\hline 1 & 0.932 & 31.003 & 13 & 0.003 \\
\hline
\end{tabular}

As there are only two groups, namely, Group-1 (Groups formed in 2005 and before) and Group-II (Groups formed after 2005) a linear discriminant analysis was attempted and it produced a single discriminant function, and the smaller Eigen values indicate that very little total dispersion was accounted by the analysis. The canonical correlation measures the association between the discriminant scores and the groups and values closer to 1 indicate strong correlation between the discriminant scores and the groups and in the current study, there is moderate ievels of correlation exist between the scores and the groups.
Table 3 displays Eigen values, the percentage of variance, the cumulative percentage and canonical correlations for canonical variable (or canonical discriminant function). The Eigen value (0.073) is the ratio of the inter-groups sum of squares to the intra-groups sum of squares. The square root of each Eigen value provides an indication of the length of the corresponding Eigen vector. Small Eigen values result in Eigen vectors of essentially no length and account for very little of the total dispersion. The canonical correlation measures the association between the discriminant scores and the groups. The value 0.260 , a fairly larger value, indicates a strong correlation between the discriminant scores and the groups.

Table 3 Eigenvalues and Measure of Fit

\begin{tabular}{|l|c|c|c|c|}
\hline Function & Eigen Value & $\begin{array}{l}\text { Percentage } \\
\text { of Variance }\end{array}$ & $\begin{array}{l}\text { Cumulative } \\
\text { Percentage }\end{array}$ & $\begin{array}{l}\text { Canonical } \\
\text { Correlation }\end{array}$ \\
\hline 1 & 0.073 & 100 & 100 & 0.260 \\
\hline
\end{tabular}

Source: Output of SPSS

Discriminant loadings have been used as a basis for interpretations. Discriminant loadings, also known as structure correlations, measure the simple linear correlation between each independent variable and the discriminant function (Hair et al 2003). It reflects the variance that the independent variables share with the discriminant function and can be interpreted to explain how much each variable contributed to the discriminant function (Table 4). The structure matrix provides within group correlations of each of the predictor variable with the canonical discriminant function. Another way to interpret the coefficients is how much each variable is useful to the discriminant function. Rotation of leaders is a major problem and constraint discriminating the older groups from the recently formed groups followed by the lack of cooperation and family member criticism.
The mature or older group members are very particular about the rotation of leaders in the groups and the newly formed groups and the groups to be formed in future should ensure the rotation of leadership. Next variable considered is lack of cooperation among members. Really it is very difficult to remain as a group with a certain goals and objectives in rural areas and the model reveals that the older groups faced the problem of lack of cooperation among members. Lack of cooperation affects the sustainability of the groups in the long run and in some cases drop outs were observed. These findings concur with the views of Ssendi and Anderson (2009) who reported that lack of trust among the members in Tanzania as a problem of SHG. Criticism by the family members is the next variable and it is the criticism of the family members that will 
affect the women and this variable also contributed to the model. The non-members of SHG also criticize the women and this variable takes precedence followed by problems in marketing, availability of raw materials and inadequate loan amount which are normally considered are major problems and constraints by the administrators and NGOs. Rotation of leaders, lack of cooperation and family member criticism are the variables that contributed most to the function respectively.

Table 4 Structure Matrix

\begin{tabular}{|l|c|}
\hline Variables in the analysis & $\begin{array}{c}\text { Function } \\
1\end{array}$ \\
\hline Rotation of leaders & .702 \\
\hline Lack of cooperation & .561 \\
\hline Family member criticism & .456 \\
\hline Non member criticism & .380 \\
\hline Problems in marketing & .337 \\
\hline Lack of time & -.316 \\
\hline Non availability of raw material & .306 \\
\hline Criticism by banks & .210 \\
\hline Inadequate loan amount & -.165 \\
\hline Lack of training & -.144 \\
\hline Lack of support in family & .108 \\
\hline Delay in getting loan & .076 \\
\hline Outsiders problem & .045 \\
\hline
\end{tabular}

Source: Output of SPSS

Standardizing the coefficients allows us to examine the relative standing of the measurements. The coefficients of the canonical variable are used to compute a canonical variable score for each case.

The standardised Canonical Discriminant function coefficient allows us to make the interpretations easier when the variables are measured on different scales. Standardised coefficient allows examining the relative importance of each of the variables in the model (Table 5).
Table 5 Standardised Canonical Discriminant Function Coefficients

\begin{tabular}{|lc|}
\hline $\begin{array}{c}\text { Variables in the discriminant } \\
\text { Function }\end{array}$ & $\begin{array}{c}\text { Function } \\
1\end{array}$ \\
\hline Family member criticism & .312 \\
\hline Non member criticism & .419 \\
\hline Criticism by banks & -.110 \\
\hline Lack of training & -.158 \\
\hline Lack of time & -.472 \\
\hline Lack of support in family & .002 \\
\hline Inadequate loan amount & -.197 \\
\hline Delay in getting loan & -.265 \\
\hline Non availability of raw material & .097 \\
\hline Problems in marketing & .484 \\
\hline Lack of cooperation & .043 \\
\hline Rotation of leaders & .462 \\
\hline Outsiders problem & -.092 \\
\hline
\end{tabular}

Source: Output of SPSS

The standardized discriminator function is

\section{$Z=0.312$ (Family member criticism) +0.419 (Non member criticism) + .002 (Lack of support in family) +0.097 (Non availability of raw material) +0.484 (Problems in marketing) +0.043 (Lack of cooperation) +.462 (Rotation of leaders)}

The variables which are found with higher importance in discriminating the groups with favourable evaluations from those with unfavourable evaluations are the problems in marketing $(0.484)$ followed by lack of time (0.482) and rotation of leaders (0.462) factors. The other variables included in the discriminating model are non member criticism (0.419), family member criticism (0.312) and delay in getting loans $(0.265)$.

The study reveals that there exists a significant difference between the two groups i.e. Group I and Group II and the study concludes that rotation of leaders, lack of cooperation and family member criticism are the major problems and constraints faced by the rural women in Vellore district. 


\section{CONCLUSION}

The discriminant model concludes that there exists a significant difference between the set of variables between the groups formed earlier and recently formed groups; the old groups faced more problems than the recently formed groups and rotation of leaders, lack of cooperation among the members and family member criticism are the major problems contributing to this significant difference. The findings concur with the studies of APMAS (2005;2006), Kumari and Malathi (2009) in India and Ssendi and Anderson (2009) in Tanzania.

\section{SUGGESTIONS}

Group management training programmes and team management training programmes may be organised by the NGOs and the rotation of leadership may be ensured by the SHPIs,NGOs, banks and other development agencies while forming, nurturing and monitoring the groups. NGOs, SHG promoting institutions and rural development practitioners have to take effective steps to sort out the issues of group conflicts and rotation of leadership be ensured from the group formation stage itself and it is the lesson to be learned from the matured SHGs and if followed by all stakeholders it will ensure the sustainability of the SHG movement in India, which is the homeland of SHG movement.

\section{REFERENCES :}

Abdul Rahman, Abdul Aziz. (2002). Poverty alleviation through micro finance in Malaysia: Potential and Constraints. Afro Asian Journal of Rural Development, .XXXV (2):7-26

Anmad, Mokbul Morshed(2006). The NGO Debate in Development: A review. In Globalising rural development. Ed:M.C.Behra. New Delhi: Sage Publications, pp 183-203.

APMAS. (2005).SHG BANK LINKAGE: A Study in Andhra Pradesh Hyderabad: A.P. Mahila Abhivvruddhi Society.

APMAS and EDA Rural System (2006). SELF HELP GROUPS IN INDIA: A study of the lights and shades. Hyderabad: A.P.Mahila Abhivruddhi Society.

Bhuvaneswaran V. (2006) Role of NGOs in Self Help Groups. HRD Times, 18(12): 24-25
Chaim,G.V.(2006).Impact of micro finance scheme. HRD Times,. 18(10): 25-27

Chethan, Vanitha and B. Krishnamurthy. (2004).Swarnajayanthi Grama Swarozgar Yojana for empowerment of Rural women in Karnataka. In: Communication and Empowerment of Women vol. $2 \mathrm{Ed}$ : Kiran Prasad. New Delhi: The women press, 2004.pp558-591.

Ghate,Prabhu.(2007). Indian Microfinance: The challenges of rapid growth. New Delhi:Sage publications.

Kallur.M.S.(2009).Micro credit through SHGs for promotion of Rural Development in Karnataka:The present and the future. In Micro Credit and Rural Development. Ed:Anil Kumar Thakur and Praveen Sharma. New Delhi: Deep \&Deep Publications,pp 6479.

Kumari,A. and N. Malathi (2009). Micro credit and rural development. In Micro Credit and Rural Development Ed:Anil Kumar Thakur and Praveen Sharma. New Delhi:Deep \&Deep Publications,.pp1-10.

Lalitha.N.(2007). Grass Root Entrepreneurship: Glimpses of Self Help Groups. Dominant Publishers and Distributors, New Delhi.

Ramanunny.M., (2005). Poverty Reduction through Micro Enterprise development in Kerala, India. In: Alleviating Poverty. Eds: Vineetha Menon, P.R.Gopinathan Nair and K.N.Nair. NOIDA: Rainbow Publishers.

Rao, M.V. (2005). Socio-Economic Development of Women: A case study of Self Help Groups in Midnapore District. In: Decentralised Planning and Participating Rural Development. Ed: Purnendu Sekhar Das. New Delhi: Concept Publishing Company, pp 155-172

Swain, Bijay (2009). Capacity building of SGHs through effective training. Professional Banker, IX, (1):52-56.

Vadivoo, Senthil. K. and V.Sekar (2004.) Self Help Groups - Movement for women empowerment, Kisan world, 31(7):13-14.

Wenner, Mark and Geoffrey Chalmers(2001). Microfinance Issues and Challenges in the Anglophone Caribbean, Washington: Inter-American Development Bank. 